\title{
The interaction between gut microbiota and age-related changes in immune function and inflammation
}

Thea Magrone* and Emilio Jirillo

\begin{abstract}
Intestinal microbiota and gut immune systems interact each other, maintaining a condition of homeostasis in the context of the intestinal habitat. However, both systems undergo modifications in elderly, thus accounting for a low grade inflammatory status which, in turn, may evolve toward more severe pathological conditions such as inflammatory bowel disease and colon rectal cancer. In addition, in western societies dietary habits may negatively influence the microbiota composition, also altering gut immune response which is per se impaired in elderly. In order to prevent the outcome of aged-related disease, supplementation of nutraceuticals able to correct abnormalities of both immune system and microbiota has become more frequent than in the past. In this respect, a better identification of components of the aged microbiota as well as a deeper analysis of gut mucosal immunity function should be pursued.
\end{abstract}

Keywords: Ageing, Gut, Immunity, Microbiota

\section{Introduction}

The intestinal microbiota is mostly confined in the colon where resides $1.5 \mathrm{Kg}$ of microbes that is equal to about $10^{14}$ microorganims [1]. Human microbiota represents a "superorganism" possessing more genes than the human genome [2]. It undergoes individual variations in its composition and, in the same individual, variations in the different segments of the bowel have been reported [3]. Moreover, the microbiota of the mucosa seems to differ from that of the lumen and not always a direct interaction between microbiota and epithelial cells does occur [4]. Actually, two major phyla have been identified in the animal and human microbiota, such as Bacteroidetes (Gram-negative bacteria) and Firmicutes (Gram-positive bacteria). However, Actinobacteria and Protobacteria can predominantly colonize the intestine in some people $[5,6]$.

In the context of the gut associated lymphoid tissue (GALT), enterocytes or intestinal epithelial cells (IECs) represent the first barrier against invading microorganisms either secreting mucin or defensins (a class of antimicrobial peptides) or sensing pathogens via Toll-like

\footnotetext{
* Correspondence: thea.magrone@libero.it

Department of Basic Medical Sciences, Neuroscience and Sensory Organs, University of Bari, Policlinico, Piazza G. Cesare 11, 70124, Bari, Italy
}

receptors (TLRs) [7]. Furthermore, microfolding (M) cells, specialized IEC, are able to sample microbial antigens and transfer them to lamina propria (LP) immune cells [e.g., dendritic cells (DCs)] [8]. In turn, DCs act as presenting antigen cells (APCs), thus triggering both harmful and protective responses in the host [9]. DCs in the presence of a milieu enriched in interleukin (IL)- 6 , IL-1 $\beta$ and transforming growth factor (TGF) $\beta$ are able to polarize the immune response towards $\mathrm{T}$ helper $(\mathrm{h}) 17$ cells which, in turn, release IL-17A, IL-17 F, IL-21 and IL-22, thus becoming inflammatory in the presence of IL-23 [10]. This immune pathway is mainly activated in the course of inflammatory bowel disease (IBD).

On the other hand, CD103+ cells are tolerogenic and in the presence of IL-10, TGF- $\beta$, thymic stromal lymphopoietin and vasoactive intestinal peptide induce $\mathrm{T}$ regulatory (Treg) cells [11]. These CD4 + CD25 + FoxP3+ cells release IL-10 in the bowel, counteracting the activity of Th17 cells [12]. This tolerogenic anti-inflammatory activity is favored by retinoic acid (RA), a metabolite of vitamin A, produced by CD103+ tolerogenic DCs [13]. Of note, RA seems to directly interfere with Th17 polarization. In the context of intestinal mucosa, secretory
C Biomed Central 
(s) IgA production by B cells prevents bacterial adhesion to mucosal surfaces and neutralize toxins.

Regulation of the intestinal immune homeostasis by the microbiota is illustrated in Figure 1.

In aged GALT, a marked multiple impairment of the immune response has been reported as evidenced by several studies conducted in animal models [14]. Major alterations are represented by [15]:

1. Reduced secretion of mucus and $\alpha$-defensin;

2. Easy entry of pathogens into the mucosal layers and generation of a low grade inflammatory response (the so-called "inflamm-ageing") [16] with Th1, Th2 and Th17 cell polarization.

This condition of inflamm-ageing [16] is perpetuated by overgrowth of intestinal pathobionts.

\section{Interactions between intestinal microbiota and immune system}

Microbiota and immune cells actively interact within the gut [17]. Evidence has been provided that Bacteroides fragilis induces production of IL-10 by Treg cells via

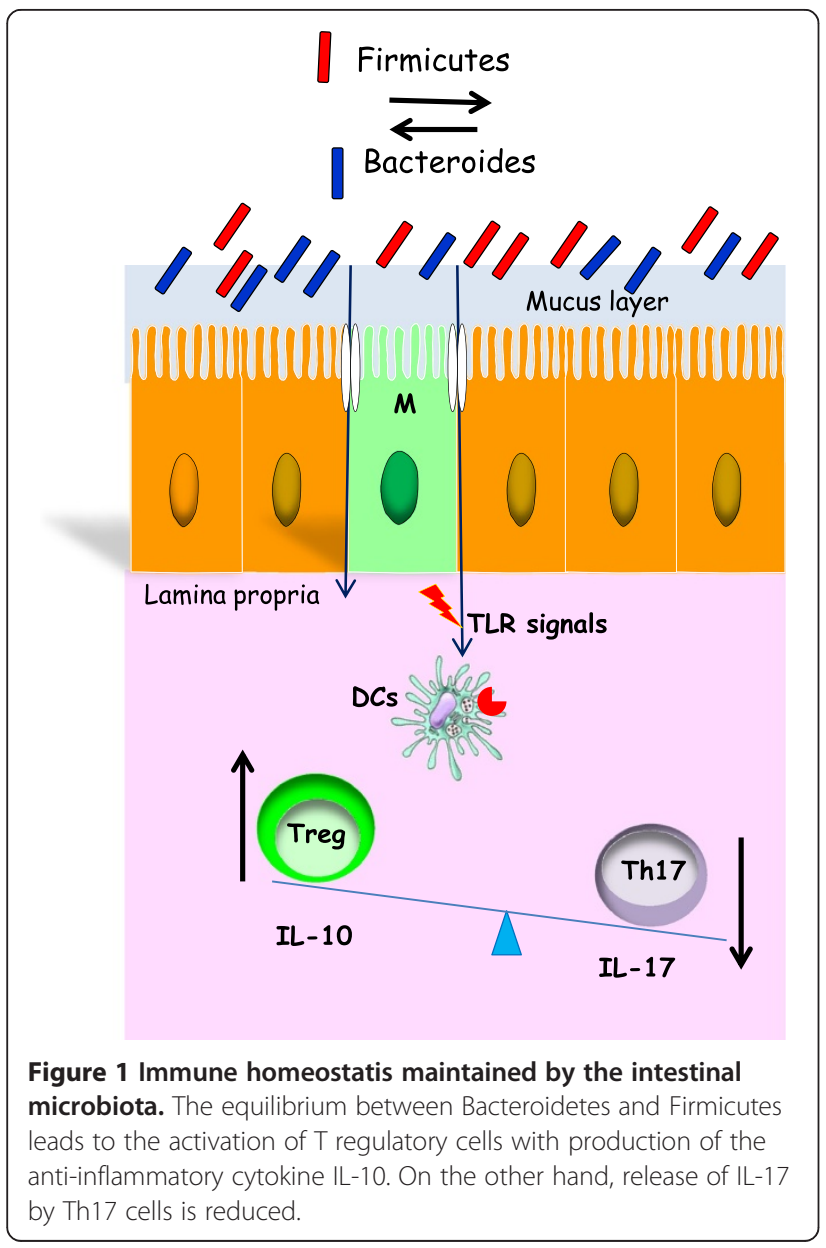

recognition of the polysaccharide A by TLR-2 [18]. In addition, lactobacilli and bifidobacteria play a tolerogenic role, rendering DCs less undifferentiated [19]. Conversely, segmented filamentous bacteria (SFB), component of the animal microbiota, are able to induce production of IL-17 from Th17 cells in mice [20]. Therefore, a fine balance is required in the daily interplay between microbiota and innate and adaptive immune cells to avoid noxious reactions to the host. According to the two-hit model [21] alteration of the microbiota triggers IL-6 production by lamina propria DCs, thus leading to activation of T0 cells. Differentiation of T0 cells into Th1 cells and Th17 cells creates an inflammatory milieu which culminates in colitis (Figure 2).

Studies on the aged intestinal microbiota have led to conflicting results. A decline of bifidobacteria and lactobacilli has been reported in the elderly with an increase of Bacteroides and facultative anaerobes [22,23]. In contrast, others reported higher levels of Ruminococcus and

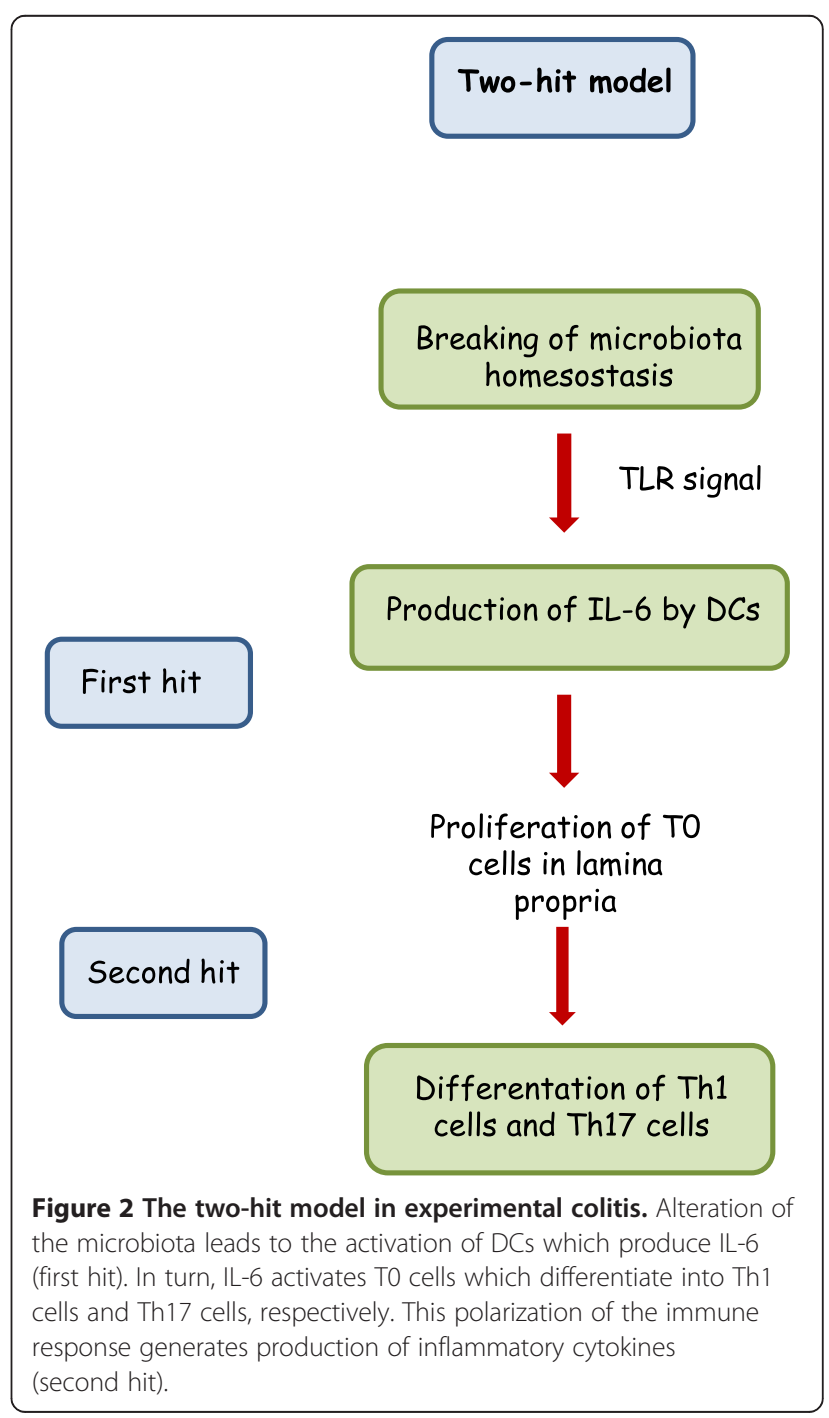


lower levels of Eubacterium and Bacteroides [24] with higher levels of bifidobacteria in comparison with the younger counterpart [25]. Finally, no differences between aged and younger individuals have been reported by others except for higher numbers of aerobes in elderly [26]. Also differences in aged microbiota were found depending on the country examined. In this respect, in a small population of aged Italian subjects an unchanged level of Bacteroidetes and an increase in Faecalibacterium spp. were observed [27]. Viceversa in a large cohort of Irish elderly people Bacteroidetes and Faecalibacterium spp. remarkably increased [22]. In the above mentioned group of Italian people no differences in microbiota were found when young adults ( 30 yrs old) and elderly (70 yrs old) were compared. Conversely, in the same group, centenarians exhibited a different composition of their microbiota. While Bacteroidetes and Firmicutes were still present with levels comparable to those of younger adults, a decrease of Clostridium cluster XIVa, an increase in bacilli and rearrangement of Clostridium cluster IV were reported [27]. In addition, in centenarians the observed increase in Proteobacteria, the so-called "pathobionts", may explain the high frequency of infections once these bacteria have escaped from the host immune response [28].

Microbiota components account for the production of short chain fatty acids (SCFA) and, in particular butyrate, acetate and propionate. SCFA are endowed with antiinflammatory (inhibition of NF- $\mathrm{kB}$ ) and anti-neoplastic activities, also exerting a protective function in favor of intestinal epithelia [29]. In fact, butyrate has been shown to provide energy to the intestinal epithelium, as suggested by epithelial atrophy and inflammation in diversion colitis owing to SCFA deficiency [30]. In aged people, evidence has been provided that reduction of butyrate levels is depending on the decreased number of Faecalibacterium (F.) prausnitzii, Eubacterium hallii and Eubacterium rectal/Roseburia group [27]. Therefore, SCFA decrease may lead to an impaired secretion of mucins by the IECs and, therefore, easier entry of pathogens into the intestinal mucosa, especially Enterobacteriaceae. These Gramnegative bacteria are able to release lipopolysaccharides or endotoxins, which, in turn, aggravate the inflammatory condition [31]. In general terms, patients with IBD exhibit an abnormal microbiota with instability of dominant species which is higher than in healthy controls. In particular, F. Prausnitzii is severely reduced in Chron's disease and in ulcerative colitis with an increased prevalence of adherent-invasive $E$. coli strains. However, the question is still open whether this alteration of microbiota is the cause or the consequence of IBD [32]. Moreover, evidence has been provided for a decreased content of SCFA in colon rectal cancer (CRC) with an increase of CRC in the western elderly population. A condition of chronic inflammation dependent on the change of microbiota leading to
TLR-mediated NF- $\kappa B$ activation and colonization of the bowel by toxigenic bacterial strains, such as Helicobacter pylori, Bacteroides fragilis and Escherichia coli seems to contribute to the pathogenesis of CRC [33]. In this framework, in a recent study a comparison of aged microbiota was made between community-dwelling individuals and long-stay individuals. Actually, SCFA fecal content was more pronounced in community group than in long-stay patients [34]. In the latter, IL-6, IL-8 and C-reactive protein levels were higher than in the former group, as expression of a status of systemic inflammation. All these evidences correlated to a change in microbiota since in community individuals a higher numbers of Firmicutes and lower numbers of Bacteroidetes than those observed in long-stay patients were detected [34]. This situation is depicted in Figure 3 where the activation of Th17 cells leads to a condition of inflammation.

In this context, one should emphasize that obesity leads to an alteration of intestinal microbiota with an increase of Firmicutes [35], thus provoking a further aggravation of inflamm-ageing.

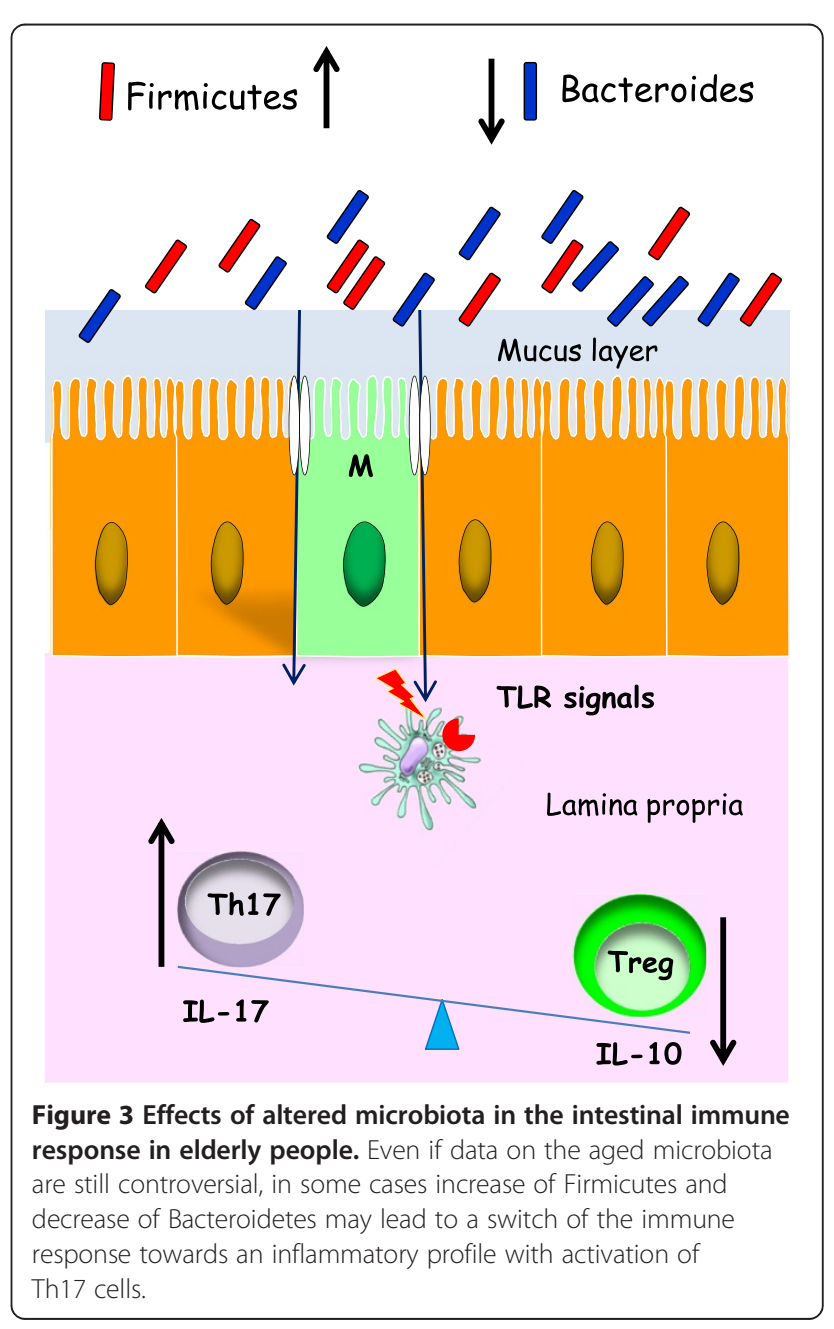




\section{Nutraceutical interventions in elderly}

Nowadays, an arsenal of dietary products is available for the restoration of microbiota in young and elderly population [36]. Prebiotics, as non digestible components of fruits, vegetables and grain, are oligosaccharides able to accelerate the growth of gut anaerobes with production of SCFA [29,37]. Probiotics are viable bacteria [38] which enhance intestinal epithelial functions such as production of mucus, defensins and sIgA [39]. Moreover, probiotics upregulate phagocytic and natural killer (NK) cell functions, also inducing activation of Treg cells [40-42]. Probiotics and symbiotics (a mix of prebiotics and probiotics) have been proven to be beneficial when administered to aged people. For instance, supplementation of Bifidobacterium (B.) lactis HN 019 to aged individuals led to the recovery of granulocyte and NK cell activities [43]. Oral intake of Lactobacillus (L.) pentosus strain b240 (b240) has been shown to augment sIgA secretion in elderly people. Moreover, b240 was able to reduce frequency of common cold in aged individuals, likely acting via mucosal immunity [44]. In a doubleblind trial B. lactis BL-01 and B. bifidum BB-02 along with inulin as a prebiotic could increase numbers of B. bifidum and total bifidobacteria and lactobacilli in the microbiota of elderly subjects [45]. Modification of microbiota seems to represent an essential event for less frequency of winter infections to occur. In a recent trial, administration for one month of fermented cow milk containing L. rhamnosus and oligofructose (a symbiotic) to free-living elderly increased serum levels of IL-1, IL-6, and IL-8, while reduced basal levels of IL-12, IL-10 and tumor necrosis factor (TNF)- $\alpha$ were not modified by this treatment [46]. It is likely that induction of a more vigorous acute phase response in these subjects may compensate the impaired adaptive immune response in the case of pathogen invasion.

Main functions of prebiotics and probiotics are represented in Figure 4.

Polyphenols, compounds widely present in the vegetal kingdom, have been shown to influence the composition of the gut microbiota. Consumption of blueberry [47], grape juice [48] and red wine or gin [49], respectively, mainly increased Bifidobacterium spp. in fecal samples from human volunteers. In addition, our recent studies have demonstrated that polyphenols contained in red wine or in fermented grape marc exhibit an anti-inflammatory role both in vitro [50] and in vivo [51]. Particularly, in vitro induction of human Treg cells and in vitro attenuation of colitis in mice with decrease of IL- $1 \beta$ and TNF- $\alpha$ content in homogenized colon seem to sustain the antiinflammatory activities of polyphenols. Therefore, intake of dietary polyphenols in the elderly may beneficially act either on microbiota restoration and, consequentially, on attenuation of chronic inflammatory conditions.

In this framework, deficiencies of micronutrients (e.g., zinc) as well as vitamin B12 have been reported in the elderly, thus accounting for frailty in the host [52,53]. However, the relationship between oligoelements and vitamin B12 and intestinal microbiota deserves further investigation in elderly.

\section{Conclusion}

In conclusion, more studies are needed for a better comprehension of the interplay between human microbiota and gut immune cells in elderly. In fact, inter individual variations of microbiota composition mostly depending on the type of diet, life style as well use of different molecular techniques of bacterial identification seem to represent the major difficulties in this area of research. In this direction, in a very recent editorial Sartor [54] has pointed out the emergence of certain strains of sulphate-reducing Deltaprotobacteria, e.g., Bilophila (B.) wadsworthia, which induces colitis in mice through release of interferon- $\gamma$ by Th1 cells. Quite interestingly, B. wadsworthia is increased in patients with ulcerative colitis, thus suggesting the need to identify new subsets of patients with IBD using Deltaprotobacteria as biomarkers [55]. It appears that consumption of saturated milk fat led to expansion of B. wadsworthia in mice [55]. Therefore, the possibility that also in humans changes of

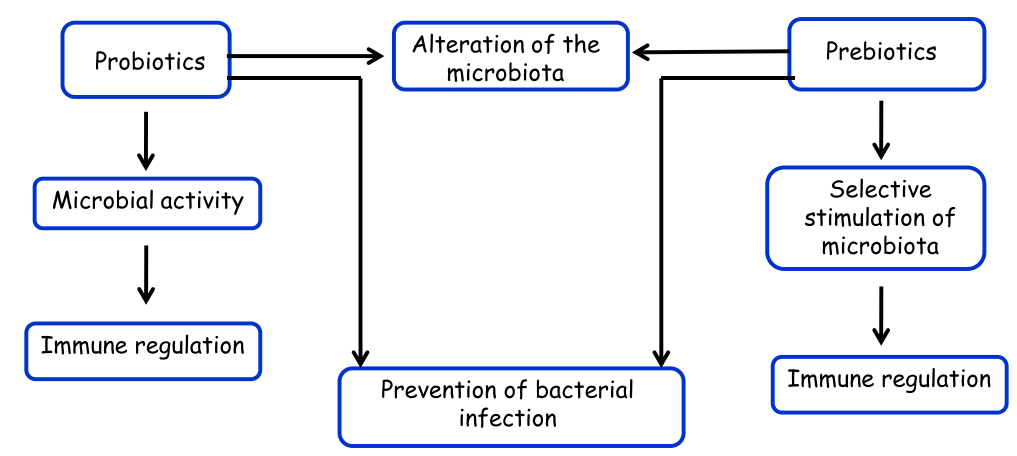

Figure 4 Illustration of major activities of probiotics and prebiotics. 
microbiota could be induced by milk-fat intake should be taken into consideration. On the other hand, in spite of many advances in the field of mucosal immunity, agerelated changes, which occur at mucosal surface, are still not completely explored. Most of the present knowledge is related to studies in rodent models, while a few investigations have been conducted on the human aged mucosal immunity. In order to overcome this problem the use of humanized mice may help in the understanding of mucosal immunity in elderly and, for instance, constructing effective vaccines to combat infectious diseases, as well as targeting specific components of the intestinal microbiota with the supplementation of nutraceuticals seem to represent the major therapeutic intervention [56,57].

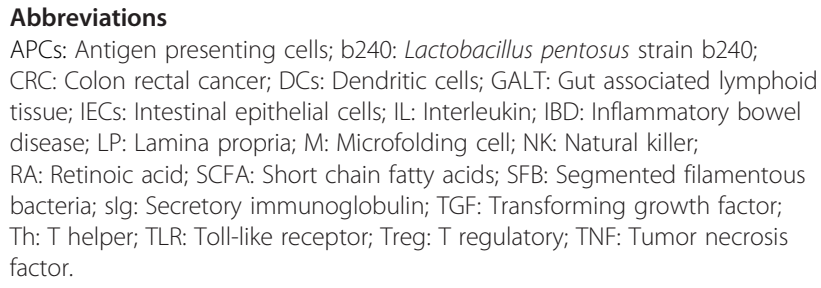

\section{Competing interests}

Both authors declare that they have no competing interests.

\section{Authors' contributions}

TM and EJ equally contributed. Both authors read and approved the final manuscript.

\section{Acknowledgements}

Paper supported in part by an intramural grant (ex 60\%) from the University of Bari, Bari, (Italy).

Received: 23 November 2012 Accepted: 10 May 2013

Published: 5 August 2013

\section{References}

1. Moore WE, Holdeman LV: Human fecal flora: the normal flora of 20 Japanese-Hawaiians. Appl Microbiol 1974, 27:961-979.

2. Ley RE, Peterson DA, Gordon Jl: Ecological and evolutionary forces shaping microbial diversity in the human intestine. Cell 2006, 124:837-848.

3. Ouwehand A, Vesterlund S: Health aspects of probiotics. IDrugs 2003, 6:573-580.

4. Zoetendal EG, von Wright A, Vilpponen-Salmela T, Ben-Amor K, Akkermans $A D$, de Vos WM: Mucosa-associated bacteria in the human gastrointestinal tract are uniformly distributed along the colon and differ from the community recovered from feces. Appl Environ Microbiol 2002, 68:3401-3407.

5. Eckburg PB, Bik EM, Bernstein CN, Purdom E, Dethlefsen L, Sargent M, Gill $\mathrm{SR}$, Nelson KE, Relman DA: Diversity of the human intestinal microbial flora. Science 2005, 308:1635-1638.

6. Louis P, Scott KP, Duncan SH, Flint HJ: Understanding the effects of diet on bacterial metabolism in the large intestine. J Appl Microbiol 2007, 102:1197-1208.

7. Miron N, Cristea V: Enterocytes: active cells in tolerance to food and microbial antigens in the gut. Clin Exp Immunol 2012, 167:405-412. doi:10.1111/j.1365-2249.2011.04523.x.

8. Kraehenbuhl JP, Neutra MR: Epithelial M cells: differentiation and function. Annu Rev Cell Dev Biol 2000, 16:301-332.

9. Iwasaki A: Mucosal dendritic cells. Annu Rev Immunol 2007, 25:381-418.
10. Kanai T, Mikami Y, Sujino T, Hisamatsu T, Hibi T: RORyt-dependent IL-17A-producing cells in the pathogenesis of intestinal inflammation. Mucosal Immunol 2012, 5:240-247. doi:10.1038/mi.2012.6.

11. Maldonado RA, von Andrian UH: How tolerogenic dendritic cells induce regulatory T cells. Adv Immunol 2010, 108:111-165.

12. Hadis U, Wahl B, Schulz O, Hardtke-Wolenski M, Schippers A, Wagner N, Müller W, Sparwasser T, Förster R, Pabst O: Intestinal tolerance requires gut homing and expansion of FoxP3+ regulatory T cells in the lamina propria. Immunity 2011, 34:237-246.

13. Agace WW, Persson EK: How vitamin A metabolizing dendritic cells are generated in the gut mucosa. Trends Immunol 2012, 33:42-48.

14. Dicarlo AL, Fuldner R, Kaminski J, Hodes R: Aging in the context of immunological architecture, function and disease outcomes. Trends Immunol 2009, 30:293-294.

15. Biagi E, Candela M, Turroni S, Garagnani P, Franceschi C, Brigidi P: Ageing and gut microbes: perspectives for health maintenance and longevity. Pharmacol Res 2012. doi:10.1016/j.phrs.2012.10.005.

16. Larbi A, Franceschi C, Mazzatti D, Solana R, Wikby A, Pawelec G: Aging of the immune system as a prognostic factor for human longevity. Physiology (Bethesda) 2008, 23:64-74.

17. Magrone T, Jirilo E: The interplay between the gut immune system and microbiota in health and disease: nutraceutical intervention for restoring intestinal homeostasis. Curr Pharm Des 2013, 9(7):1329-1342.

18. Round JL, Mazmanian SK: Inducible Foxp3+ regulatory T-cell development by a commensal bacterium of the intestinal microbiota. Proc Natl Acad Sci U S A 2010, 107:12204-12209.

19. Davies JM, Sheil B, Shanahan F: Bacterial signalling overrides cytokine signalling and modifies dendritic cell differentiation. Immunology 2009, 128(Suppl 1):e805-e815.

20. Ivanov II, Atarashi K, Manel N, Brodie EL, Shima T, Karaoz U, Wei D, Goldfarb KC, Santee CA, Lynch SV, Tanoue T, Imaoka A, Itoh K, Takeda K, Umesaki Y, Honda K, Littman DR: Induction of intestinal Th17 cells by segmented filamentous bacteria. Cell 2009, 139:485-498.

21. Feng T, Wang L, Schoeb TR, Elson CO, Cong Y: Microbiota innate stimulation is a prerequisite for $T$ cell spontaneous proliferation and induction of experimental colitis. J Exp Med 2010, 207:1321-1332. doi:10.1084/jem.20092253.

22. Claesson MJ, Cusack S, O'Sullivan O, Greene-Diniz R, de Weerd H, Flannery E, Marchesi JR, Falush D, Dinan T, Fitzgerald G, Stanton C, van Sinderen D, O'Connor M, Harnedy N, O'Connor K, Henry C, O'Mahony D, Fitzgerald AP, Shanahan F, Twomey C, Hill C, Ross RP, O'Toole PW: Composition, variability, and temporal stability of the intestinal microbiota of the elderly. Proc Natl Acad Sci U S A 2011, 108(Suppl 1):4586-4591.

23. Hopkins MJ, Sharp R, Macfarlane GT: Age and disease related changes in intestinal bacterial populations assessed by cell culture, $16 \mathrm{~S}$ rRNA abundance, and community cellular fatty acid profiles. Gut 2001, 48:198-205.

24. He T, Harmsen HJ, Raangs GC, Welling GW: Composition of faecal microbiota of elderly people. Microb Ecol Health Dis 2003, 15:153-159.

25. Harmsen HJ, Wildeboer-Veloo AC, Grijpstra J, Knol J, Degener JE, Welling GW: Development of 16S rRNA-based probes for the Coriobacterium group and the Atopobium cluster and their application for enumeration of Coriobacteriaceae in human feces from volunteers of different age groups. Appl Environ Microbiol 2000, 66:4523-4527.

26. Tiihonen K, Ouwehand AC, Rautonen N: Human intestinal microbiota and healthy ageing. Ageing Res Rev 2010, 9:107-116.

27. Biagi E, Nylund L, Candela M, Ostan R, Bucci L, Pini E, Nikkila J, Monti D, Satokari R, Franceschi C, Brigidi P, De Vos W: Through ageing, and beyond: gut microbiota and inflammatory status in seniors and centenarians. PLoS One 2010, 5:e10667.

28. Pédron T, Sansonetti P: Commensals, bacterial pathogens and intestinal inflammation: an intriguing ménage à trois. Cell Host Microbe 2008, 3:344347.

29. De Vuyst L, Leroy F: Cross-feeding between bifidobacteria and butyrateproducing colon bacteria explains bifdobacterial competitiveness, butyrate production, and gas production. Int J Food Microbiol 2011, 149:73-80.

30. Ioannidis O, Varnalidis I, Paraskevas G, Botsios D: Nutritional modulation of the inflammatory bowel response. Digestion 2011, 84:89-101.

31. Schiffrin EJ, Morley JE, Donnet-Hughes A, Guigoz Y: The inflammatory status of the elderly: the intestinal contribution. Mutat Res 2010, 690:50-56. 
32. Manichanh C, Borruel N, Casellas F, Guarner F: The gut microbiota in IBD. Nat Rev Gastroenterol Hepatol 2012, 9:599-608. doi:10.1038/ nrgastro.2012.152.

33. Kraus S, Arber N: Inflammation and colorectal cancer. Curr Opin Pharmacol 2009, 9:405-410.

34. Kinross J, Nicholson JK: Gut microbiota: dietary and social modulation of gut microbiota in the elderly. Nat Rev Gastroenterol Hepatol 2012, 9:563-564. doi:10.1038/nrgastro.2012.169.

35. Ley RE, Turnbaugh PJ, Klein S, Gordon Jl: Microbial ecology: Human gut microbes associated with obesity. Nature 2006, 444:1022-1023. doi:10.1038/4441022a.

36. Candore G, Caruso C, Jirillo E, Magrone T, Vasto S: Low grade inflammation as a common pathogenetic denominator in age-related diseases: novel drug targets for anti-ageing strategies and successful ageing achievement. Curr Pharm Des 2010, 16:584-596.

37. Roberfroid M, Gibson GR, Hoyles L, McCartney AL, Rastall R, Rowland I, Wolvers D, Watzl B, Szajewska H, Stahl B, Guarner F, Respondek F, Whelan K, Coxam V, Davicco MJ, Léotoing L, Wittrant Y, Delzenne NM, Cani PD, Neyrinck AM, Meheust A: Prebiotic effects: metabolic and health benefits. Br J Nutr 2010, 104(Suppl 2):S1-S63.

38. Hume ME: Historic perspective: prebiotics, probiotics, and other alternatives to antibiotics. Poult Sci 2011, 90:2663-2669.

39. Wallace TC, Guarner F, Madsen K, Cabana MD, Gibson G, Hentges E, Sanders ME: Human gut microbiota and its relationship to health and disease. Nutr Rev 2011, 69:392-403. doi:10.1111/j.1753-4887.2011.00402.x

40. de LeBlanc AM, Castillo NA, Perdigon G: Anti-infective mechanisms induced by a probiotic Lactobacillus strain against Salmonella enterica serovar Typhimurium infection. Int J Food Microbiol 2010, 138:223-231.

41. Macpherson AJ, Slack E: The functional interactions of commensal bacteria with intestinal secretory IgA. Curr Opin Gastroenterol 2007, 23:673-678

42. Kwon HK, Lee CG, So JS, Chae CS, Hwang JS, Sahoo A, Nam JH, Rhee JH, Hwang KC, Im SH: Generation of regulatory dendritic cells and CD4 + Foxp3+ T cells by probiotics administration suppresses immune disorders. Proc Natl Acad Sci U S A 2010, 107:2159-2164.

43. Gill HS, Rutherfurd KJ, Cross ML, Gopal PK: Enhancement of immunity in the elderly by dietary supplementation with the probiotic Bifidobacterium lactis HN019. Am J Clin Nutr 2001, 74:833-839.

44. Shinkai S, Toba M, Saito T, Sato I, Tsubouchi M, Taira K, Kakumoto K, Inamatsu T, Yoshida H, Fujiwara Y, Fukaya T, Matsumoto T, Tateda K, Yamaguchi K, Kohda N, Kohno S: Immunoprotective effects of oral intake of heat-killed Lactobacillus pentosus strain b240 in elderly adults: a randomised, double-blind, placebo-controlled trial. Br J Nutr 2012:1-10. http://dx.doi.org/10.1017/S0007114512003753.

45. Bartosch S, Woodmansey EJ, Paterson JC, McMurdo ME, Macfarlane GT: Microbiological effects of consuming a synbiotic containing Bifidobacterium bifidum, Bifidobacterium lactis, and oligofructose in elderly persons, determined by real-time polymerase chain reaction and counting of viable bacteria. Clin Infect Dis 2005, 40:28-37.

46. Amati L, Marzulli G, Martulli M, Pugliese V, Caruso C, Candore G, Vasto S, Jirillo $E$ : Administration of a synbiotic to free-living elderly and evaluation of serum cytokines. A pilot study. Curr Pharm Des 2010, 16:854-858.

47. Vendrame S, Guglielmetti S, Riso P, Arioli S, Klimis-Zacas D, Porrini M: Sixweek consumption of a wild blueberry powder drink increases bifidobacteria in the human gut. J Agric Food Chem 2011, 59:12815-12820.

48. Jacobs DM, Deltimple N, van Velzen E, van Dorsten FA, Bingham M, Vaughan EE, van Duynhoven J: (1)H NMR metabolite profiling of feces as a tool to assess the impact of nutrition on the human microbiome. NMR Biomed 2008, 21:615-626.

49. Queipo-Ortuño Ml, Boto-Ordóñez M, Murri M, Gomez-Zumaquero JM, Clemente-Postigo M, Estruch R, Cardona Diaz F, Andrés-Lacueva C, Tinahones FJ: Influence of red wine polyphenols and ethanol on the gut microbiota ecology and biochemical biomarkers. Am J Clin Nutr 2012, 95:1323-1334

50. Magrone T, Marzulli G, Jirillo E: Immunopathogenesis of neurodegenerative diseases: current therapeutic models of neuroprotection with special reference to natural products. Curr Pharm Des 2012, 18:34-42

51. Kawaguchi K, Matsumoto T, Kumazawa Y: Effects of antioxidant polyphenols on TNF-alpha-related diseases. Curr Top Med Chem 2011, 11:1767-1779.
52. Mocchegiani E, Costarelli L, Giacconi R, Piacenza F, Basso A, Malavolta M: Micronutrient ( $\mathrm{Zn}, \mathrm{Cu}, \mathrm{Fe}$ )-gene interactions in ageing and inflammatory age-related diseases: implications for treatments. Ageing Res Rev 2012, 11:297-319. doi:10.1016/j.arr.2012.01.004

53. Dhonukshe-Rutten RA, Lips M, de Jong N, Chin A, Paw MJ, Hiddink GJ, van Dusseldorp M, De Groot LC, van Staveren WA: Vitamin B-12 status is associated with bone mineral content and bone mineral density in frail elderly women but not in men. J Nutr 2003, 133:801-807.

54. Sartor RB: Gut microbiota: Diet promotes dysbiosis and colitis in susceptible hosts. Nat Rev Gastroenterol Hepatol 2012, 9:561-562. doi:10.1038/nrgastro.2012.157

55. Devkota S, Wang Y, Musch MW, Leone V, Fehlner-Peach H, Nadimpalli A, Antonopoulos DA, Jabri B, Chang EB: Dietary-fat-induced taurocholic acid promotes pathobiont expansion and colitis in II10-/- mice. Nature 2012, 487:104-108.

56. Fujihashi K, Kiyono H: Mucosal immunosenescence: new developments and vaccines to control infectious diseases. Trends Immunol 2009, 30:334-343.

57. Rehman T: Role of the gut microbiota in age-related chronic inflammation. Endocr Metab Immune Disord Drug Targets 2012, 12(4):361-367.

\section{doi:10.1186/1742-4933-10-31}

Cite this article as: Magrone and Jirillo: The interaction between gut microbiota and age-related changes in immune function and inflammation. Immunity \& Ageing 2013 10:31.

\section{Submit your next manuscript to BioMed Central and take full advantage of:}

- Convenient online submission

- Thorough peer review

- No space constraints or color figure charges

- Immediate publication on acceptance

- Inclusion in PubMed, CAS, Scopus and Google Scholar

- Research which is freely available for redistribution 